\title{
Living Space and Psychological Well-being in Urban China: Differentiated Relationships across Socio-economic Gradients
}

\author{
Author Accepted Manuscript \\ Journal: Environment and Planning $A$ \\ Yang Hu (yang.hu@lancaster.ac.uk) \\ Rory Coulter (rcc46@cam.ac.uk)
}

\begin{abstract}
Western research has shown that a shortage of living space is associated with poor psychological well-being. By contrast, norms and practices of extended family co-residence, collectivist social organization and a bureaucratic quota-based housing allocation system were thought to limit the adverse psychological effects of cramped dwelling conditions in pre-reform China. As these buffers may be weakening with the dramatic housing reforms, socio-economic and cultural changes taking place in post-reform urban China, we use data from the 2010 China Family Panel Studies $(N=13,367)$ to re-examine the relationship between living space and psychological well-being in contemporary Chinese cities. In particular, we examine the ways in which this relationship is moderated by family wealth and community poverty in order to explore how subjective experiences of dwelling space are shaped by one's relative socio-economic position. The results show that cramped living conditions are significantly associated with poor psychological well-being in post-reform urban China. Importantly, the psychological implications of cramped dwellings may vary with family and particularly community socio-economic status as this association tends to be stronger amongst more affluent families and communities than among those that are more impoverished. Taken together the findings indicate that uneven socio-economic development, segmented cultural change and drastic housing reforms within China's cities may be interacting to configure people's housing experiences and health outcomes.
\end{abstract}

\section{Key words}

China, Living Space, Psychological Well-being, Family Wealth, Community Poverty 


\section{INTRODUCTION}

Article 25 of the 1948 United Nations Universal Declaration of Human Rights asserts that access to suitable housing is crucial for human well-being. A basic requirement of suitable housing is adequate living space and in many countries "overcrowded" conditions are taken to indicate housing deprivation (Filandri and Olagnero, 2014). Decades of Western research have indicated that a shortage of dwelling space adversely affects psychological well-being (Booth, 1976; Evans and Lepore, 1992; Evans et al., 2003; Gove et al., 1983). In contrast, norms and practices of multigenerational co-residence and collectivist social organization were traditionally thought to limit the links between living space and psychological well-being in pre-reform China, as people valued living with extended families and aligned their space expectation with this distinctive cultural preference (Booth, 1976; Fuller et al., 1993; Huang, 2003; Silverstein et al., 2006). These discrepant findings from Western research and pre-reform China indicate that dwelling space expectations, experiences and psychological responses to housing conditions are subjective, relatively determined and contingent on contextual circumstances (Arku et al., 2011).

In 1978 China's economic reforms instigated a period of dramatic social and cultural upheaval by transforming the economy from centralized state control into a market-oriented system. In post-reform urban China, collective socialist ideals and patrilocal traditions are in decline (Cheung and Kwan, 2009; Hu, 2016), while individualism is rapidly rising (Yan, 2009). This may have weakened the cultural preference for collective living arrangements and extended family coresidence - most notably among the urban affluent ( $\mathrm{Hu}, 2016)$ - thus propelling increased demands for personal space. Meanwhile, China's population growth, urbanization and mass rural-to-urban migration have led to soaring population density and intensified housing pressure in urban areas (Cui et al., 2015; Huang, 2003). There is good reason to believe that these contextual changes may have significantly re-configured people's relative space expectations and access to dwelling space, which could have uneven psychological consequences across the urban population. The first objective of this research is therefore to re-examine how living space is associated with psychological well-being in post-reform urban China.

Although many studies concentrate on the population-level links between living space and psychological well-being (Dunn, 2002; Dunn and Hayes, 2000; Evans et al., 2003), differential access to resources and the context dependent nature of housing expectations and opportunities mean that psychological responses to living space could vary with individual and community socio-economic position. This variation is important because China now has 
one of the highest levels of family wealth disparity in the world (Xie and Jin, 2015). The country's rapid yet uneven economic growth and urbanization has also led to an uneven spread of poverty across neighborhood communities and the emergence of urban "ghettoes" (Wang, 2004).

Differences in family and community socio-economic position may influence people's psychological responses to living space because ideals and practices pertaining to collective social organization and extended family coresidence are detraditionalized to varying degrees along the socio-economic ladder (Hu, 2016; Yan, 2009). This uneven detraditionalization means that living arrangement preferences and dwelling space expectations may vary across the socio-economic spectrum (Hu, 2016; Yan, 2009), particularly as people normalize such expectations with reference to others living in the same community. At the same time, the transition from a quota-based housing system to a more privatized and commodified housing market means that living space is increasingly tied to purchasing power (Chen and Gao, 1993; Cui et al., 2015; Huang, 2003; Huang and Li, 2014). This may generate differentiated space expectations and give rise to distinct housing contraints which could have heterogeneous psychological implications across socioeconomic gradients. Our second objective is therefore to assess whether the relationship between living space and psychological well-being varies with the socio-economic status of families and communities.

We limit our focus to urban China because Chinese cities are at the forefront of housing reforms as well as socio-economic and cultural changes. Moreover, the pressure to accommodate more than 160 million rural-to-urban migrants every year (China National Bureau of Statistics, 2013) means that the Chinese population is rapidly urbanizing and this shift is placing great strain on housing resources in Chinese cities (Chen et al., 2011). By concentrating on urban China we aim to shed new light on the relative and context dependent nature of "crowding" as is subjectively experienced by individuals from distinct socioeconomic strata.

\section{BACKGROUND}

\subsection{Living Space and Psychological Well-being}

Western research has long suggested that cramped living conditions may adversely affect psychological well-being and other health outcomes (Conley, 2001; Gove et al., 1983). Several mechanisms may explain the association between cramped living conditions and poor psychological well-being (Arku et al., 2011; Dunn, 2002). Conley (2001) posits that cramped 
living conditions could lower well-being by reducing privacy, generating stress, disrupting sleep patterns or daily routines and making it harder to have fulfilling family and social interactions. On a more symbolic level, in affluent communities and societies a lack of living space may also act as an unwelcome social signifier of poverty and an inability to meet mainstream consumption norms (Filandri and Olagnero, 2014). Finally, the association between limited space and poor psychological well-being could be a correlated consequence of the other forms of housing deprivation that are disproportionately experienced by poor households living towards the bottom end of housing markets. These could include affordability problems, a lack of basic dwelling facilities, poor housing conditions or an undesirable local environment.

Although dwellings play an important role in processes of family formation and patrilineal inheritance in Chinese society, where the homeownership rate is as high as 90 per cent (Xinhua, 2013), in the pre-reform period there was little evidence that cramped dwellings were linked to poor psychological well-being (Booth, 1976). This discrepancy with Western research was attributed to several psychological "buffering" processes. In part, the lack of a clear association between living space and psychological well-being was ascribed to the collective organization of Chinese society in terms of widespread multigenerational coresidence and close-knit kinship and family ties (Booth, 1976; Cheng et al., 2014; Wang, 2004). Moreover, it was believed that crowded dwellings and a lack of privacy were normalized in East Asian societies with high population densities (Fuller et al., 1993; Huang, 2003). These factors were thought to act as psychological buffers by lowering space expectations and making living space less influential in assessments of well-being. This lowered the chances that people's housing experiences would fail to live up to their expectations and limited the psychological consequences of cramped housing conditions.

In 1978, widespread reforms marked the beginning of China's transition from a statecontrolled centralized economy to a market system. The reforms have proceeded especially rapidly in urban areas where amongst other changes there has been a marked transition in the socio-economic profiles of families and communities. In the post-reform era, several contextual changes may be weakening the traditional buffers protecting people from the adverse psychological effects of cramped dwellings. First, population growth from 0.98 billion to 1.40 billion between 1980 and 2015 and mass urbanization have led to a substantial increase in urban population densities (Cheng et al., 2014; Wang, 2004). At the same time, the relaxation of hukou policy (the household registration system that once prohibited rural residents' mobility up the urban chain) in the 1980s has led to phenomenal rural-to-urban 
migration (Chan and Zhang, 1999). In 2012, more than 160 million rural Chinese had migrated to urban areas (China National Bureau of Statistics, 2013), adding severe pressure to the country's crowded urban centers where many people now live in very cramped conditions (Cui et al., 2015).

New patterns of dwelling preference and space expectation may also have been created by the structural and ideational changes in urban Chinese families that have occured in the post-reform era (Hu, 2016). A rising tide of individualization has been accompanied by a shift from multigenerational co-residence to the nuclear family model (Cheung and Kwan, 2009; Yan, 2009). Moreover, as China's economic reforms exposed urban and coastal areas to the influence of Western culture, individual space and personal privacy have become more respected, while the influence of collectivism and familism has declined (Yan, 2009). Overall, given these social and cultural changes we would expect a relatively limited access to living space to be associated with worse psychological well-being in post-reform urban China. This leads to our first hypothesis:

Hypothesis 1: Lower access to living space is associated with lower psychological well-being in post-reform urban China.

\subsection{Differentiated Associations across Socio-economic Gradients}

Much prior research examines the population-level links between living space and psychological well-being (Arku et al., 2011; Dunn, 2002). This approach overlooks the highly relative and contextually conditioned nature of perceptions of normal or adequate living space and thus neglects the subjective dimension of housing expectations and experiences. Although Sundstrom $(1978,32)$ defined "crowding" as "a state of psychological stress that sometimes accompanies high population density [in the household]", what is considered "high population density" or alternatively a lack of living space may not be the same for everyone. In this view psychological distress occurs when there is a relative mismatch between one's normative space expectation and the space one can access (Dunn, 2002; Dunn and Hayes, 2000). As a result, assessments of dwelling space sufficiency could vary geographically and across social groups with the varying preferences people have and the distinct points of reference they use to define their expectations (Baum, 1978; Fuller et al., 1993).

To help formulate hypotheses about how family and community socio-economic position may moderate the relationship between dwelling space and psychological well-being, we first devise a conceptual framework that emphasizes the relative and contextually 
conditioned construction of space expectations and experiences. In this framework individuals hold relatively unconstrained space desires which are shaped by the ways in which housing requirements are formulated and evaluated within the context of distinct cultural preferences such as patrilocal traditions. The likelihood of realizing these desires is then self-reflexively assessed through considerations of resource access and the availability and affordability of housing, leading individuals to adapt their desire into a more constrained but more realistic space expectation (Coulter et al., 2011). Crucially, the translation of space desires into space expectations is a relational process as expectations are constructed, validated and normalized through interactions and comparisons with similar others (Fuller et al., 1993; Hagerty and Veenhoven, 2003). As housing is an important life domain, fulfilling these space expectations then becomes important for psychological well-being.

In the pre-reform period, housing was allocated based on occupational rank; and despite some social gradation in dwelling space, the quota-based allocation system largely followed socialist egalitarian ideals (Huang, 2003; Huang and Li, 2014). This means that individuals were unlikely to have space expectations that exceeded their allocated quota. This changed in 1988 when a national housing reform forcibly transformed China's welfareoriented housing system into a more privatized and commodified part of the market economy (Chen and Gao, 1993). The deinstitutionalization of the quota-based system and the commodification of housing have opened up new housing options and allowed for inflation of space expectations (Huang and $\mathrm{Li}, 2014$ ). The reforms also mean that both expectations of and access to living space are increasingly tied to command of socio-economic resources $(\mathrm{Li}$, 2000; Huang and Li, 2014). Meanwhile, China's economic reform also entailed accruing socio-economic disparities as well as divergent cultural preferences between the affluent and the impoverished (Hu, 2016; Xie and Hu, 2014; Xie and Jin, 2015). This means that relative socio-economic position could play an increasingly crucial role in the construction of space expectations, thereby generating differences in how people from across the socio-economic spectrum respond psychologically to given quantities of dwelling space (Chen and Gao, 1993; Li, 2000; Wu et al., 2012).

On the one hand, affluent people are more likely to endorse a cultural preference for personal space and thus expect to live in a more spacious dwelling as they are more exposed to ideals of individualism and have less adherence to traditional conventions of multigenerational co-residence (Martin, 1990; Yan, 2009). Their command of socioeconomic resources and thus purchasing power could also fuel consumption expectations (Cheng et al., 2014; Huang, 2003; Huang and Jiang, 2009; Li, 2000), which may be 
reinforced and normalized by exposure to like-minded peers with spacious dwellings (Hagerty and Veenhoven, 2003). As in developed Western societies, amongst the affluent housing may thus be a source of social status, with spacious homes signalling symbolic success.

However, in many cases it may be tricky for affluent families to fulfil their space expectations. Juggling multiple housing priorities such as location, neighborhood environment, public facilities such as school, medical centers and transport means that the affluent will often have to trade acquiring dwelling space off against a desire to obtain other dwelling attributes (Wang and Li, 2004; Yuan and Hamori, 2014). Nevertheless, accepting less space in order to obtain other valued dwelling attributes might not diminish their actual space preferences and expectations (Wang and Li, 2004). The practical constraints imposed by costly housing markets therefore mean that many affluent individuals may be unable to satisfy their space expectations, potentially triggering adverse psychological consequences.

On the other hand, people who are less well-off are less affected by the rhetoric of individualization (Yan, 2009) and more often retain a traditional cultural preference for collective living arrangements and multigenerational co-residence (Cheung and Kwan, 2009). This could make housing conditions less relevant for their psychological well-being and mean that although the poor tend to live in cramped dwellings, their seemingly "objective" need for more dwelling space may not translate into high subjective space expectations. Moreover as reported by Whyte (2010), Chinese people perceive it to be an individual rather than institutional responsibility to cope with social inequalities by adjusting one's expectations and working one's own way up the socio-economic ladder. As a result, the impoverished may hold themselves to be responsible for their own living conditions. This could mean they actively align their space expectations with their limited socio-economic means in order to avoid the harmful cognitive dissonance generated by a limited ability to access spacious dwellings (Arku et al., 2011; Booth, 1976; Festinger, 1962; Fuller et al., 1993). Therefore despite practical constraints, it is less likely that poor people's housing experiences will fail to meet their space expectations when compared with the affluent. We therefore hypothesize:

Hypothesis 2: The association between living space and psychological well-being is stronger amongst people from affluent families than those from more impoverished families.

Crucially, socio-economic disparities are not only an individual-level phenomenon in post-reform urban China. The country's rapid urbanization, housing market reforms and the 
establishment of new commercial-housing districts in large cities have also led to a spatial segregation of poverty and affluence at the community level-most visibly through the rise of poverty-stricken neighborhoods (Wang, 2007; Wang, 2004). As housing expectations are context dependent and relationally shaped by local peer group interactions, these differences in neighborhood socio-economic status could moderate how people respond psychologically to dwelling space.

In impoverished neighborhoods, access to spacious dwellings is constrained by limited stock and a lack of financial resources to move to better-off neighbourhoods. This could lead residents to downgrade their space expectations to avoid the harmful cognitive dissonance that could result if their expectations cannot be fulfilled. Moreover, limited living space may also have few psychological implications for people from impoverished communities because they have relatively low space expectations as they construct and normalize their expectations in relation to others from the same community who live in similarly cramped dwellings.

By contrast, the well-being of people from affluent communities may be more tied to their living space. Living amongst wealthier neighbors with spacious dwellings, high space expectations and command of socio-economic resources mean that people from affluent neighborhoods may have a lower psychological tolerance for residential crowding and a strong desire for space (Cheng et al., 2014; Li, 2000; Wang, 2007). However, high housing prices in affluent neighborhoods may make it difficult for residents to fulfill their expectations, which could have adverse consequences for psychological well-being. This suggests a final hypothesis:

Hypothesis 3: The association between living space and psychological well-being is stronger in more affluent communities than in communities with high poverty rates.

\section{DATA AND METHOD}

\subsection{Data and Sample}

The data for this study were drawn from the 2010 baseline wave of the China Family Panel Studies (hereafter CFPS, http://www.isss.edu.cn/cfps/en/ for details). The CFPS is conducted by the Institute of Social Science Survey at Peking University in collaboration with the Population Studies Center at the University of Michigan. The adult panel of the 2010 wave consisted of face-to-face computer-assisted personal interviews with 33,600 people aged 16 years and above living in 16,000 households, of whom 15,584 respondents were living in urban areas under the jurisdiction of neighborhood committees as opposed to rural 
village committees. Multi-stage probability-proportional-to-size sampling was used with samples weighted in proportion to population structures at the administrative levels of province, county, neighborhood community, and household. This means that the data have a hierarchical structure with individuals nested in households and communities. The response rate of $81.28 \%$ compares very favorably with many Western social surveys (Xie and $\mathrm{Hu}$, 2014).

Before running the analyses we eliminated 2,217 cases with missing values on key variables such as living space, psychological well-being, family wealth and community poverty. Correlation analyses were conducted to assess the selectivity of item non-response and these revealed no significant associations between missing values and key demographic characteristics such as age, gender, etc. (Pearson's $r<.02$ for all tests). In total 13,367 urban adults providing valid information for key variables were used for the analyses ( $\sim 86$ per cent of the original CFPS urban sample). Their detailed characteristics are described in the results section.

\subsection{Key Measures}

Psychological Well-being. Respondents' answers to six separate questions were used to gauge their psychological well-being. These questions asked people to report how often in the last month they felt (a) depressed, (b) nervous, (c) restless, (d) hopeless, (e) that life is meaningless and (f) how often they experienced mental difficulties performing daily tasks. Answers were provided on a five-point Likert scale ranging from "never (0)" through "sometimes (1)", "often (2)", "around half the time (3)" to "almost daily (4)". Exploratory factor analysis shows that the six items form one factor with an eigenvalue above 1.

Cronbach's alpha test also indicated a high level of internal consistency between the six items $(\alpha>.80)$. As each measure contributed a fairly similar factor loading we summed each person's responses to the six questions to derive a composite index of psychological wellbeing ranging from 0 to 17 . We then reversed the index so that a higher score indicates greater well-being.

Living Space. The head of each household was asked to report the size of the urban dwelling in which they currently live in square meters - a standard and widely used measure of dwelling space in China. Following prior research on dwelling space pressure (e.g. Fuller et al., 1993; Huang, 2003) we calculated living space in per capita $\mathrm{m}^{2}$ by dividing the size of each dwelling by the number of routine residents. 
Family Wealth. Household heads were asked to estimate the value of the family's wealth holdings in Chinese yuan. We calculated total family wealth as the sum of a comprehensive set of assets, which is detailed by Xie and Jin $(2015,205)$ to include "housing assets, financial assets (e.g., savings, stock, funds, bonds, financial derivatives, and other financial assets), agricultural machinery, business assets, detailed items of durable goods (valuables included), and liabilities from housing and other sources". Although Western research shows that estimates of wealth holdings can be imprecise, Xie and Jin (2015) report that this family wealth measure performs well as an indicator of relative affluence in China.

Community Poverty. We use the community poverty rate as a proxy for neighborhood socio-economic status. In addition to the household and individual interviews, the CFPS contains a community panel gathering contextual data about each surveyed neighborhood (in urban areas) or village community (in rural areas). Neighborhood communities have populations of up to 10,000 (Xie and $\mathrm{Hu}, 2014$ ). For the community panel knowledgeable local informants such as cadres and officials were surveyed to provide basic information about the community. Instead of setting an arbitrary wealth or income threshold for poverty, a good indicator is households' eligibility for dibao low-income subsidy (Wang, 2007). Eligibility is calculated by local government by assessing whether household income per capita falls below a local threshold deemed sufficient to provide a minimum standard of living. The community panel of the CFPS contains measures for the number of households eligible for (but not necessarily claiming) dibao and the total number of households in a given community. We calculated poverty rates by dividing the former by the latter.

\subsection{Covariates}

We control for a range of individual, household and community characteristics which may affect living space and/or psychological well-being. In addition to a gender dummy we include age as a linear regressor (preliminary work showed this to be the most parsimonious specification). Respondents' marital status was measured using a categorical variable distinguishing the "never married", "currently married" and "previously married". Due to small numbers we combined the divorced and widowed. We control for years of schooling to capture the impact of education on socio-economic standing and cultural perceptions of adequate living space.

Given China's large rural-urban gulf and phenomenal internal migration, we used people's hukou status (i.e. household registration distinguishing between rural and urban types) to identify rural-to-urban migrants as those who have rural hukou but reside in urban 
areas. As labor force status affects access to resources we defined a categorical measure of economic activity to separate individuals who are not working, those employed in nonagricultural sectors, those working in agriculture (e.g. private farm produce vendors), the retired and those currently in education.

Because physical health affects psychological well-being (Easterlin, 2006) we include respondents' self-reported physical health on a five-point scale ranging from "good health (1)" to "poor health (5)". Past research found an association between solo living and poor psychological well-being (Yeung and Cheung, 2015) and so we take into account whether respondents live on their own. We also experimented with including a series of life course event dummies such as recent divorce, unemployment, childbirth and widowhood as these types of events are known to shape psychological well-being. However, perhaps because this is a cross-sectional rather than longitudinal study, the results indicated that only recent divorce had a marginally significant association with psychological well-being.

Finally, a battery of dwelling-related characteristics are used to disentangle the psychological impacts of living space from the effects of other housing attributes. A dummy variable was included to identify people with dwelling-related debts such as mortgages or loans from relatives, as difficulties with housing finance have been shown to negatively affect psychological health in Western countries (Taylor et al., 2007). Housing tenure was measured as a categorical variable differentiating between homeowners, those living in employer provided housing, renters and dwellings provided by extended family members. We also control for dwelling type using a categorical variable identifying flat blocks, bungalows, siheyuan (a traditional Chinese dwelling composed of bungalows around a central courtyard), house (with at least two floors) and other types of dwelling. The head of each household was asked to estimate the market price of the dwellings in which they currrently live at the time of the survey. We calculated the unit dwelling price as a continuous variable in units of $1,000 \mathrm{yuan} / \mathrm{m}^{2}$. In cases $(\sim 22$ per cent of the analytical sample) where the market price of dwelling was unreported because the dwelling was rented or provided by an employer, we replaced the missing values with the mean values within neighborhood communities because unit housing prices are often fairly similar within neighborhoods (Huang, 2003). We log-transformed this variable to account for its skewed distribution. It is worth noting that the replacement of missing values with community-level means may reduce the variance of dwelling prices and lead to underestimated coefficients on the housing price variable (Johansson and Karlsson, 2013). The results based on mean replacements are robust to alternative methods such as casewise deletion and multiple imputation. 


\subsection{Analytic Strategy}

As there is little representative evidence on housing space consumption in post-reform urban China, we begin by examining the correlates of living space per capita. To do this we fit a multilevel model with random intercepts at the community level to examine how individual, familial and (unobserved) community characteristics are associated with living space per capita (Snijders and Bosker, 2012). We do not include a family level random intercept because living space per capita is measured at this level. All continuous variables are grand mean centered. This means that the intercept reflects average living space per capita when all categorical variables are set to the reference category and all continuous variables take their sample means.

To test the hypotheses, we then fit multilevel models with random intercepts at the family (level two) and community (level three) levels to examine the relationship between living space per capita and psychological well-being. In Model A, we examine the main effect of living space, net of all other variables. To examine how socio-economic position moderates the relationship between living space and psychological well-being, we then include cross-level interaction terms between living space per capita and family wealth (logged) and community poverty respectively in Model B and C. Based on Model B and C, we then provide an intuitive illustration of the interaction effects by graphing the predictive margins of psychological well-being by living space per capita, at the $10^{\text {th }}, 25^{\text {th }}, 50^{\text {th }}, 75^{\text {th }}$ and $90^{\text {th }}$ percentiles of family wealth and community poverty rate respectively.

To check the robustness of our results we conducted a number of sensitivity checks (results not shown but available on request). The reported results are robust to the exclusion of outliers on the dependent variable (psychological well-being falling outside $+/-3$ standard deviations); the specification of psychological well-being as a categorical variable in terms of whether one reported having experienced more than one of the six negative psychological symptoms; as well as alternative subjective well-being measurements such as overall life satisfaction.

\section{RESULTS}

\subsection{Descriptive Results}

Table 1 describes the sample and shows that the overall distribution of psychological well-being is slightly skewed towards higher well-being. The mean age of respondents is 46 and 52 per cent of respondents are male. The average length of schooling years is 8.10 years, 
which is near to the completion of China's 9-year compulsory education (middle school). In keeping with previous research, around 44 per cent of urban residents are rural-to-urban migrants and 10 per cent live alone (China National Bureau of Statistics, 2013; Yeung and Cheung, 2015). The mean family wealth is 279,300 yuan ( 1 Chinese yuan $\approx 0.145$ US dollars), with a median of 50,000 yuan. The average community poverty rate is around 8 per cent but this ranges from 0 up to 51 per cent.

\section{[Insert Table 1 Here]}

Table 1 shows that sample members typically reported living in dwellings measuring 110 square meters. The average number of 2.72 routine residents per dwelling is consistent with trends towards smaller households as the nuclear family replaces traditions of multigenerational co-residence. Overall families typically report around 46 square meters of living space per capita. In our sample, 81 per cent of individuals are homeowners. This is lower than the 90 per cent national figure reported elsewhere (Xinhua, 2013), perhaps because a considerable proportion of rural-to-urban migrants do not own the urban properties in which they reside. Roughly 19 per cent of people have dwelling-related debts such as mortgages or loans from their extended family. Around 42 per cent of respondents live in flat blocks that are typical in urban China, approximately 26 per cent live in bungalows, 2 per cent in traditional siheyuan and 25 per cent in houses with more than one-storey. The reported average unit housing price of 9,640 yuan per square meter is close to transaction records of around 9,042 yuan per square meter in urban China in 2009-2010 (China Real Estate Index System, 2010).

\subsection{Correlates of Living Space}

Table 2 presents the results for the random-intercept model predicting living space per capita. No significant gender difference is apparent. Age is positively associated with living space per capita, which is consistent with Western notions of "housing careers" whereby people tend to move to more spacious and higher quality dwellings as they age and accumulate resources (Clark et al., 2003). Unsurprisingly, people who live on their own have much more living space per capita than those living with others.

[Insert Table 2 Here]

Table 2 shows that living space per capita is positively associated with socioeconomic status as proxied by years of education. The positive association between labor force participation and living space is not statistically significant, perhaps because individuals' economic activity status is already partially captured by their family wealth. Interestingly, 
dwelling-related debts are associated with larger living space, presumably because people borrow to purchase more spacious dwellings. In China employers often provide on-site accommodation for staff and it is also common for extended families to provide living space as a part of kinship support. However, our results show that dwellings provided by employers and extended families tend to be relatively cramped. Renters also live in more cramped dwellings than homeowners.

As might be expected, living space per capita increases with family wealth $(p<.001)$ and decreases with the community poverty rate $(p<.10)$. The latter finding suggests that dwelling stock tends to be less spacious in poorer neighborhoods, which is likely to constrain less affluent households' opportunities to move to spacious dwellings. Housing price also has a significant negative association with living space per capita. This is important as it indicates that commanding socio-economic resources does not free affluent families from well-off communities from having to make housing attribute tradeoffs, probably because housing prices tend to be higher in less impoverished neighborhoods $(r=-.24, p<.001)$ and wealthy families tend to purchase expensive dwellings $(r=.27, p<.001)$.

\subsection{Living Space and Psychological Well-being}

Table 3 presents the results from three-level random-intercept models predicting psychological well-being. To intuitively illustrate how the association between living space and psychological well-being tends to vary with family wealth and community poverty, Figure 1 presents the predictive margins of this association at the $10^{\text {th }}, 25^{\text {th }}, 50^{\text {th }}, 75^{\text {th }}$ and $90^{\text {th }}$ percentiles of family wealth and community poverty rate respectively.

[Insert Table 3 and Figure 1 Here]

The results from Model A support Hypothesis 1 as greater living space is significantly associated with enhanced psychological well-being in post-reform urban China $(p<.05)$. This indicates that we cannot assume that norms and practices of multigenerational coresidence and high population densities buffer individuals from the psychological implications of limited living space in the post-reform era (c.f. Booth, 1976).

Although the results from Model B show that the interaction term between family wealth and living space is small and not statistically significant, the upper panel of Figure 1 depicts how the slope of the living space effect on the predicted level of psychological wellbeing tends to vary across family wealth percentiles. The figure suggests that the association tends to be somewhat stronger for individuals from the top percentiles of family wealth; and the strength of association (steepness of slope) seems to decrease as we move down the 
socio-economic ladder from the $90^{\text {th }}$ to the $10^{\text {th }}$ percentile of family wealth. These results are broadly in line with Hypothesis 2 as the association between living space and psychological well-being appears to be slightly stronger among more affluent than impoverished families.

The results from Model C support Hypothesis 3 as community poverty significantly moderates the relationship between living space and psychological well-being. Unlike in Model B, this time the interaction effect is statistically significant at the 1 per cent level. The predictions in the lower panel of Figure 1 show that the slope of living space on psychological well-being is steeper for people from affluent communities than for those from poverty-stricken communities (at the top percentiles of poverty rate). The strength of association between living space per capita and psychological well-being therefore decreases as we move from affluent communities to comparably worse-off communities. This may be because people from affluent communities tend to have more individualized space preferences and also align their (higher) space expectations with other wealthy families living in the same community. By contrast, low space expectations and limited connection between space and well-being may be the norm in impoverished communities where few people have spacious homes and people lack the resources and opportunities to move to larger dwellings.

Revisiting Table 3 reveals other important factors associated with psychological wellbeing in post-reform urban China. Consistent with findings from Western research (Meisenberg \& Woodley, 2014), women report a significantly higher level of psychological well-being than men. Net of other factors levels of psychological well-being increase slightly with age. Married respondents report greater psychological well-being than respondents who are not married. Unsurprisingly, recent divorce is associated with reduced psychological well-being $(p<.10)$, as are solo-living and dwelling-related debts $(p<.05)$. High housing price appears to be associated with a higher level of psychological well-being, perhaps because more expensive dwellings come with other unmeasured attractive attributes such as a desirable location, good neighborhood environment, etc. In addition to the the moderation effects discussed above, the sizeable main effects of family wealth and community poverty visible in Table 3 indicate that higher levels of community poverty and lower levels of family wealth are associated with reduced well-being. Both absolute access to resources and one's relative position across socio-economic gradients seem to be important for psychological well-being in contemporary urban China.

Taken together, the results suggest that dwelling attributes - size, type, finance and so on-are associated with psychological well-being in post-reform China. The results also indicate that people's experiences of living space are highly subjective, relative and 
moderated by family and especially community socio-economic position. In general psychological well-being is more strongly related to living space amongst people living in affluent families and prosperous communities.

\section{CONCLUSIONS AND DISCUSSION}

Western researchers have reported an association between living in cramped dwellings and reporting poor psychological well-being (Gove et al., 1983). By contrast, patrilocal traditions, extended family co-residence, a quota-based housing allocation system and a hypothesized tolerance for high population densities were thought to buffer individuals from the negative psychological consequences of cramped housing in pre-reform China (Booth, 1976). Given the magnitude and pace of China's ongoing demographic, socioeconomic and cultural transformations as well as housing reforms, it is crucial to reassess how access to living space shapes the psychological well-being of urban Chinese citizens in the post-reform era.

Our results indicate that living space is an important "health resource" in post-reform urban China, as there is a significant association between limited space and reporting lower psychological well-being. This contrast with the pre-reform period could be due to a number of contextual changes (c.f. Booth, 1976). Rapid population growth and rural-to-urban migration have increased population densities in Chinese cities, exposing more people to unprecedented levels of residential stress. Yet at the same time economic development, declining norms and traditions of both patrilocality and multigenerational co-residence, as well as a growing sense of individualism may be raising people's space expectations. Furthermore, the transition to a commercialized and privatized housing market has also opened up new housing options and lifted the restrictions on housing expectations that were previously imposed by bureaucratic quota-based allocations procedures. When taken together this underlines the highly context dependent nature of how people experience dwelling space.

Therefore, instead of conceptualizing adequate living space as something objective, we argue that people may make sense of dwelling space in diverse, subjective and relative ways, because housing expectations are relationally produced and contextually shaped. This subjective and variegated dimension of housing expectations is important because the uneven spread of social change in China may have created divergent cultural preferences regarding housing (Cheung and Kwan, 2009; Yan, 2009). Furthermore, the uneven distribution of socio-economic resources across families and communities may have generated differentiated consumption expectations and constraints (Huang and Li, 2014; Wang and Li, 2004). This is 
shown by the differentiated associations between living space and psychological well-being across the socio-economic gradient at family and particularly community levels.

On the one hand, our results suggest that there is a slightly stronger association between living space and psychological well-being amongst people from affluent families and especially affluent communities. This may be because affluent people have particularly high space expectations, as they endorse ideals such as individualism and personal privacy (Yan, 2009) whilst eschewing the traditions of collective extended family coresidence (Cheung and Kwan, 2009). Furthermore, the idea and incidence of cramped dwellings is less normalized in affluent communities, perhaps because high space expectations are relationally produced through socio-economically homogeneous peer interactions. However, the greater space expectations of the affluent may not always be easy to fulfil. Indeed we find that the affluent tend to purchase more expensive dwellings in better-off neighborhoods. This could force them to trade off paying for dwelling space against purchasing other desired housing attributes. The adverse psychological implications of juggling multiple housing desires could only become more severe for the affluent with the growing distinction between more and less "desirable" dwellings and neighborhoods in urban China (Huang and Li, 2014). This may be particularly relevant as property developers proactively engineer such distinctions to generate consumption desires by linking "desirable" dwelling with the symbolic rhetoric of projecting a "mid-upper class" identity (Li, 2000; Wang and Li, 2003).

On the other hand, there is a relatively weak association between living space and psychological well-being amongst relatively impoverished families and communities. In part this may be because people from impoverished families and communities are less affected by individualism and tend to be more oriented towards patrilocal traditions. Besides their distinct cultural preference for collective extended family coresidence, people from impoverished families and communities may also align their space expectations with their limited financial means to reduce the harmful cognitive dissonance that could arise if their expectations cannot be fulfilled. Interaction and comparison with others from similarly impoverished families and communities may further help "normalize" a lack of space and residential crowding (Hagerty and Veenhoven, 2003).

Nevertheless, it is important to consider these subjective perceptions in conjunction with objective inequalities in living space. While we find that people from relatively impoverished families and communities suffer from an objective lack of dwelling space, what is particularly problematic is that they seem "acculturated" and "coerced" to subjectively normalize cramped living conditions. This fits with Whyte's (2010) contention that Chinese 
citizens take it for granted that individuals rather than the state are responsible for distributive injustice in a neoliberal market economy. Discrepancies between an objective shortage of space and subjective perceptions of cramped dwellings may thus form one aspect of the "dormant volcano" of social injustice depicted by Whyte (2010). In this view, as development progresses, individualization creeps down the socio-economic gradient and poor people's space expectations rise, there is a looming danger that the "volcano" might erupt as citizens no longer consider limited dwelling space as being normal.

Our findings pose several challenges for future research. First, we draw on family wealth and community poverty as proxies to contextualize and differentiate between distinct cultural preferences, space expectations and housing constraints. Future work should directly measure individual perceptions in order to provide a thorough understanding of the construction of housing norms, expectations and experiences. Second, it is important to conduct longitudinal analyses to unpack the causal mechanisms underlying the dynamic relations between living space and psychological well-being across socio-economic gradients. Third, as cramped dwellings are a major motivation for residential mobility, it may be particularly important to examine the temporal dynamics underlying the interactions between dwelling space, residential mobility and well-being when more waves of the CFPS become available. Overall this research suggests that state investment in affordable housing, balanced city planning, measured urbanization and regulation of the real estate market is important for all urban citizens as it could improve the psychological well-being of the affluent as well as the housing conditions of the impoverished. 


\section{REFERENCES}

Arku G, Luginaah I, Mkandawire P, Baiden P, \& Asiedu AB (2011) Housing and health in three contrasting neighborhoods in Accra, Ghana. Social Science \& Medicine 72(11): 1864-1872.

Baum A (1978) Human Response to Crowding. L. Erlbaum Associates.

Booth A (1976) Urban Crowding and Its Consequences. Praeger.

Chan KW and Zhang L (1999) The hukou system and rural-urban migration in China: Processes and changes. The China Quarterly 160: 818-855.

Cheng Z, King S, Smith R and Wang H (2014) Housing property rights and subjective wellbeing in urban China. Department of Economics Discussion Paper 44/14, ISSN: 1441-5429.

Chen X and Gao X (1993) Urban economic reform and public-housing investment in China. Urban Affairs Review 29(1): 117-145.

Chen J, Guo F and Wu Y (2011) One decade of urban housing reform in China: Urban housing price dynamics and the role of migration and urbanization, 1995-2005. Habitat International, 35(1), 1-8.

Cheung CK and Kwan AYH (2009) The erosion of filial piety by modernisation in Chinese cities. Ageing \& Society 29(02): 179-198.

China National Bureau of Statistics (2013) Report on the monitoring survey of the nation's peasant workers (nongmingong). Available at: Www.stats.gov.cn/tjsj/zxfb/201305/t20130527_12978.html (accessed 25 July 2014).

China Real Estate Index System (2010) Trends of housing price in China. Available at: http://fdc.fang.com/ (accessed 30 November 2015:)

Clark WAV, Deurloo MC and Dieleman FM (2003) Housing careers in the United States, 1968-93: Modelling the sequencing of housing states. Urban Studies 40(1): 143-160.

Conley D (2001) A room with a view or a room of one's own? Housing and social stratification. Sociological Forum 16(2): 263-280.

Coulter, R., Ham, M. van, \& Feijten, P. (2011). A Longitudinal Analysis of Moving Desires, Expectations and Actual Moving Behaviour. Environment and Planning A, 43(11), $2742-2760$.

Cui C, Geertman S and Hooimeijer P (2015) Residential mobility of skilled migrants in Nanjing, China. Environment and Planning A 47(3): 625-642. 
Dunn JR (2002) Housing and inequalities in health: A study of socio-economic dimensions of housing and self reported health from a survey of Vancouver residents. Journal of Epidemiology and Community Health 56(9): 671-681.

Dunn JR and Hayes MV (2000) Social inequality, population health, and housing: A study of two Vancouver neighborhoods. Social Science \& Medicine 51(4): 563-587.

Easterlin RA (2006) Life cycle happiness and its sources: Intersections of psychology, economics, and demography. Journal of Economic Psychology 27(4): 463-482.

Evans GW and Lepore SJ (1992) Conceptual and analytic issues in crowding research. Journal of Environmental Psychology 12(2): 163-173.

Evans GW, Wells NM and Moch A (2003) Housing and mental health: A review of the evidence and a methodological and conceptual critique. Journal of Social Issues 59(3): $475-500$.

Festinger L (1962) A Theory of Cognitive Dissonance. CA: Stanford University Press. Filandri M and Olagnero M (2014). Housing inequality and social class in Europe. Housing Studies 29(7): 977-993.

Fuller TD, Edwards JN, Sermsri S and Vorakitphokatorn S (1993). Housing, stress, and physical well-being: Evidence from Thailand. Social Science \& Medicine 36(11): $1417-1428$.

Gove WR, Hughes MD and Galle OR (1983) Overcrowding in the Household: An Analysis of Determinants and Effects. Academic Press.

Hagerty MR and Veenhoven R (2003) Wealth and happiness revisited - Growing national income does go with greater happiness. Social Indicators Research 64(1): 1-27.

Huang Y (2003) A room of one's own: Housing consumption and residential crowding in transitional urban China. Environment and Planning A 35(4): 591-614.

Huang Y and Jiang LW (2009) Housing inequality in transitional Beijing. International Journal of Urban and Regional Research 33(4): 936-956.

Huang Y and Li SM (2014) Housing Inequality in Chinese Cities. Abingdon: Routledge. $\mathrm{Hu}$ Y (2016) Impact of rural-to-urban migration on family and gender values in China. Asian Population Studies. Online first: DOI: 10.1080/17441730.2016.1169753

Johansson ÅM and Karlsson MO (2013) Comparison of methods for handling missing covariate data. The AAPS Journal 15(4): 1232-1241.

Li S (2000) Housing consumption in urban China: A comparative study of Beijing and Guangzhou. Environment and Planning A 32(6): 1115-1134. 
Martin LG (1990) Changing intergenerational family relations in East Asia. Annals of the American Academy of Political and Social Science 510: 102-114.

Meisenberg G and Woodley MA (2014) Gender differences in subjective well-being and their relationships with gender equality. Journal of Happiness Studies 16(6): 15391555.

Snijders TA and Bosker RJ (2012) Multilevel Analysis: An Introduction to Basic and Advanced Multilevel Modeling, 2nd Edition. London: SAGE.

Sundstrom E (1978) Crowding as a sequential process: Review of research on the effects of population density of humans. In: Baum A and Epstein YM (eds) Human Responses to Crowding. Hillsdale, NJ: Erlbaum.

Taylor MP, Pevalin DJ and Todd J (2007) The psychological costs of unsustainable housing commitments. Psychological Medicine 37(7): 1027-1036.

Silverstein M, Cong Z and Li S (2006) Intergenerational transfers and living arrangements of older people in rural China: Consequences for psychological well-being. The Journals of Gerontology Series B: Psychological Sciences and Social Sciences 61(5): S256S266.

Wang D and Li SM (2004) Housing preferences in a transitional housing system: The case of Beijing, China. Environment and Planning A 36(1): 69-87.

Wang M (2007) Emerging urban poverty and effects of the dibao program on alleviating poverty in china. Social Science Research Network. Available at: papers.ssrn.com/abstract=1009710 (accessed 10 November 2015).

Wang YP (2004) Urban Poverty, Housing and Social Change in China. London: Routledge. Whyte MK (2010) Myth of the social volcano: Perceptions of inequality and distributive injustice in contemporary China. CA: Stanford University Press.

Wu J, Gyourko J and Deng Y (2012) Evaluating conditions in major Chinese housing markets. Regional Science and Urban Economics 42(3): 531-543.

Xinhua News (2013) 9 in 10 families own their homes. Available at: news.xinhuanet.com/english/china/2013-07/20/c_132558552.htm (accessed 14 April 2015).

Xie Y and Hu J (2014) An introduction to the China Family Panel Studies (CFPS). Chinese Sociological Review 47(1): 3-29.

Xie Y and Jin Y (2015) Household wealth in China. Chinese Sociological Review 47(3): 203-229.

Yan Y (2009) The Individualization of Chinese Society. London: Bloomsbury Academic. 
Yeung WJJ and Cheung AKL (2015) Living alone: One-person households in Asia.

Demographic Research S15(40): 1099-1112.

Yuan N and Hamori S (2014) Crowding-out effects of affordable and unaffordable housing in China, 1999-2010. Applied Economics 46(35): 4318-4333. 
Table 1. Sample Characteristics $(N=13,367$ individuals $)$

\begin{tabular}{|c|c|c|c|c|}
\hline Parameters & Mean & $S D$ & Min & Max \\
\hline A. Psychological well-being & 14.39 & 3.47 & 0 & 17 \\
\hline \multicolumn{5}{|l|}{ B. Individual-level characteristics } \\
\hline Gender $(0=$ female $)$ & .52 & .50 & 0 & 1 \\
\hline $\operatorname{Age}^{\mathrm{a}}$ & 45.53 & 16.14 & 16 & 82 \\
\hline \multicolumn{5}{|l|}{ Marital status } \\
\hline Never married & .13 & .34 & 0 & 1 \\
\hline Currently married & .79 & .40 & 0 & 1 \\
\hline Previously married & .07 & .26 & 0 & 1 \\
\hline Recently divorced & .01 & .09 & 0 & 1 \\
\hline Years of schooling & 8.10 & 4.87 & 0 & 16 \\
\hline \multicolumn{5}{|l|}{ Economic activity } \\
\hline Not working & .21 & .41 & 0 & 1 \\
\hline Working & .49 & .50 & 0 & 1 \\
\hline Farming & .08 & .28 & 0 & 1 \\
\hline Retired & .15 & .36 & 0 & 1 \\
\hline In education & .06 & .24 & 0 & 1 \\
\hline Rural-to-urban migrant & .44 & .50 & 0 & 1 \\
\hline Solo living & .10 & .30 & 0 & 1 \\
\hline Self-reported physical health (high = less healthy) & 1.74 & .92 & 1 & 5 \\
\hline \multicolumn{5}{|l|}{ C. Family-level characteristics } \\
\hline Family wealth $(10,000 \text { yuan })^{\mathrm{a}}$ & 27.93 & 92.46 & 0 & 631 \\
\hline Living space $\left(\mathrm{m}^{2}\right)^{a}$ & 110.17 & 77.14 & 7 & 396 \\
\hline Number of routine residents in household & 2.72 & 1.17 & 1 & 10 \\
\hline Living space per capita $\left(\mathrm{m}^{2}\right)$ & 45.54 & 33.70 & 7 & 175 \\
\hline Has dwelling-related debt (mortgage, etc.) & .19 & .39 & 0 & 1 \\
\hline \multicolumn{5}{|l|}{ Dwelling ownership } \\
\hline Owner & .81 & .39 & 0 & 1 \\
\hline Employer-provided & .04 & .19 & 0 & 1 \\
\hline Renter & .09 & .29 & 0 & 1 \\
\hline Family-provided & .06 & .23 & 0 & 1 \\
\hline \multicolumn{5}{|l|}{ Dwelling type } \\
\hline Flat block & .42 & .49 & 0 & 1 \\
\hline Bungalow & .26 & .44 & 0 & 1 \\
\hline Siheyuan (circled bungalows) & .02 & .14 & 0 & 1 \\
\hline House (two-storey) & .25 & .43 & 0 & 1 \\
\hline Other & .05 & .21 & 0 & 1 \\
\hline Unit dwelling price $\left(1,000 \text { yuan } / \mathrm{m}^{2}\right)^{\mathrm{a}, \mathrm{b}}$ & 9.64 & 4.06 & 2 & 21 \\
\hline \multicolumn{5}{|l|}{ D. Community-level characteristic } \\
\hline Community poverty rate ${ }^{a}$ & .08 & .08 & 0 & .51 \\
\hline
\end{tabular}

Note: ${ }^{\text {a }}$ Top 1 per cent replaced to be equal to the $99^{\text {th }}$ percentile to reduce the influence of outlier cases. ${ }^{\text {b }}$

Bottom 1 percent replaced to be equal to equal to the $2^{\text {nd }}$ percentile to reduce the influence of outlier cases.

Column percentages may not sum to 1 due to rounding. 
Table 2. Multilevel Random-Intercept Model Predicting Living Space Per Capita $(N=$ 13,367 individuals)

\begin{tabular}{|c|c|c|}
\hline Parameters & Coef. & S.E. \\
\hline Gender (ref = female) & .493 & .413 \\
\hline Age & .057 & $.021 * *$ \\
\hline \multicolumn{3}{|l|}{ Marital status (ref = never married) } \\
\hline Married & 6.981 & $.819 * * *$ \\
\hline Previously married & 1.306 & 1.204 \\
\hline Solo living (no) & 45.639 & $.734 * * *$ \\
\hline \multicolumn{3}{|l|}{ Economic activity (ref = not working) } \\
\hline Working & .214 & .556 \\
\hline Farming & .932 & .986 \\
\hline Retired & .668 & .782 \\
\hline In education & 2.905 & $1.168^{*}$ \\
\hline Year of schooling & .320 & $.057 * * *$ \\
\hline Rural-to-urban migrant (ref $=$ urban native) & -1.416 & $.639 *$ \\
\hline Dwelling-related debt $(\mathrm{ref}=\mathrm{no})$ & 1.679 & $.638 * *$ \\
\hline \multicolumn{3}{|l|}{ Dwelling ownership (ref = owner) } \\
\hline Employer-provided & -10.676 & $1.285^{* * *}$ \\
\hline Renter & -13.963 & $.938 * * *$ \\
\hline Family-provided & -5.526 & $.914 * * *$ \\
\hline \multicolumn{3}{|l|}{ Dwelling type (ref = flat block) } \\
\hline Bungalow & -.502 & .881 \\
\hline Siheyuan (circled bungalow) & 9.072 & $1.853 * * *$ \\
\hline House (two-storey) & 20.869 & $.888 * * *$ \\
\hline Other & -4.960 & $1.324 * * *$ \\
\hline Unit dwelling price (log) & -5.417 & $.266 * * *$ \\
\hline Family wealth $(\log )$ & .853 & $.158 * * *$ \\
\hline Community poverty rate & -26.934 & $15.829 \dagger$ \\
\hline Intercept & 33.148 & $1.444 * * *$ \\
\hline Community-level variance & 226.732 & $20.171 * * *$ \\
\hline Community level ICC & .299 & \\
\hline$A I C($ Null $=127,587)$ & \multicolumn{2}{|c|}{122,750} \\
\hline$L L($ Null $=-63,790)$ & \multicolumn{2}{|c|}{$-61,350$} \\
\hline
\end{tabular}

Note: $\mathrm{ICC}=$ Intra-Class Correlation Coefficient. AIC $=$ Akaike Information Criterion. $\mathrm{LL}=\mathrm{Log}$-Likelihood. Continuous predictors centered at their grand means.

$\dagger p<.10 ; * p<.05 ; * * p<.01 ; * * * p<.001$. 
Table 3. Multilevel Random-Intercept Model Predicting Psychological Well-being ( $N=$ 13,367 individuals)

\begin{tabular}{|c|c|c|c|c|c|c|}
\hline \multirow[b]{2}{*}{ Parameters } & \multicolumn{2}{|c|}{ Model A } & \multicolumn{2}{|c|}{ Model B } & \multicolumn{2}{|c|}{ Model C } \\
\hline & Coef. & S.E. & Coef. & S.E. & Coef. & S.E. \\
\hline Living space $p c$ & .002 & $.001 *$ & .002 & .001 & .002 & .001 \\
\hline Living space $p c \times$ family Wealth $(\log )$ & & & .001 & .001 & & \\
\hline Living space $p c \times$ community poverty & & & & & -.047 & $.016^{* *}$ \\
\hline Gender $($ ref $=$ female $)$ & -.224 & $.051 * * *$ & -.224 & $.051 * * *$ & -.225 & $.051 * * *$ \\
\hline Age & .015 & $.003 * * *$ & .015 & $.003 * * *$ & .015 & $.003 * * *$ \\
\hline \multicolumn{7}{|l|}{ Marital status (ref $=$ never married) } \\
\hline Married & .483 & $.108 * * *$ & .483 & $.108 * * *$ & .485 & $.108 * * *$ \\
\hline Previously married & -.146 & .164 & -.145 & .164 & -.137 & .164 \\
\hline Recently divorced $(\mathrm{ref}=$ no) & -.498 & $.297 \dagger$ & -.498 & $.297 \dagger$ & -.500 & $.297 \dagger$ \\
\hline Solo living $(\mathrm{ref}=\mathrm{no})$ & -.271 & $.114^{*}$ & -.257 & $.114 *$ & -.289 & $.114 *$ \\
\hline \multicolumn{7}{|l|}{ Economic activity (ref = not working) } \\
\hline Working & .213 & $.073 * *$ & .210 & $.073 * *$ & .212 & $.073 * *$ \\
\hline Farming & .243 & $.127 \dagger$ & .247 & $.127 \dagger$ & .244 & $.127 \dagger$ \\
\hline Retired & .949 & $.103 * * *$ & .947 & $.103 * * *$ & .951 & $.103 * * *$ \\
\hline In education & .049 & .152 & .045 & .152 & .046 & .152 \\
\hline Year of schooling & .020 & $.008^{* *}$ & .020 & $.008 * *$ & .020 & $.008 * *$ \\
\hline $\begin{array}{l}\text { Self-reported physical health (high }= \\
\text { unhealthy) }\end{array}$ & -1.161 & $.031 * * *$ & -1.159 & $.031 * * *$ & -1.160 & $.031 * * *$ \\
\hline $\begin{array}{l}\text { Rural-to-urban migrant (ref = urban } \\
\text { native) }\end{array}$ & .060 & .083 & .062 & .083 & .061 & .083 \\
\hline Dwelling-related debt $(\mathrm{ref}=\mathrm{no})$ & -.235 & $.096^{*}$ & -.225 & $.096^{*}$ & -.229 & $.096^{*}$ \\
\hline \multicolumn{7}{|l|}{ Dwelling ownership (ref = owner) } \\
\hline Employer-provided & .057 & .188 & .052 & .188 & .047 & .188 \\
\hline Renter & .051 & .139 & .050 & .139 & .058 & .139 \\
\hline Family-provided & -.256 & $.136 \dagger$ & -.255 & $.136 \dagger$ & -.251 & $.136 \dagger$ \\
\hline \multicolumn{7}{|l|}{ Dwelling type (ref = flat block) } \\
\hline Bungalow & .060 & .116 & .065 & .116 & .054 & .116 \\
\hline Siheyuan (circled bungalow) & .624 & $.270 *$ & .624 & $.270 *$ & .616 & $.269 *$ \\
\hline House (two-storey) & .105 & .119 & .097 & .119 & .098 & .119 \\
\hline Other & -.148 & .186 & -.144 & .186 & -.176 & .186 \\
\hline Unit dwelling price $(\log )$ & .080 & $.035^{*}$ & .079 & $.035^{*}$ & .084 & $.035^{*}$ \\
\hline Family wealth (log) & .102 & $.024 * * *$ & .092 & $.025 * * *$ & .103 & $.024 * * *$ \\
\hline Community poverty rate & -3.397 & $1.062 * *$ & -3.385 & $1.062 * *$ & -3.169 & $1.063 * *$ \\
\hline Individual-level intercept & 13.572 & $.154 * * *$ & 13.573 & $.154 * * *$ & 13.576 & $.154 * * *$ \\
\hline Community-level variance & .736 & $.082 * * *$ & .735 & $.082 * * *$ & .731 & $.082 * * *$ \\
\hline$I C C$ for community level & .071 & & .071 & & .071 & \\
\hline Family-level variance & 1.864 & $.121 * * *$ & 1.864 & $.121 * * *$ & 1.859 & $.121 * * *$ \\
\hline$I C C$ for family level & .252 & & .252 & & .252 & \\
\hline$A I C(\mathrm{Null}=69,861)$ & 68,1 & & 68,1 & & 68,1 & \\
\hline$L L($ Null $=-34,927)$ & $-34,0$ & & $-34,0$ & & $-34,0$ & \\
\hline
\end{tabular}

Note: $p c=$ per capita . ICC $=$ Intra-Class Correlation Coefficient. AIC $=$ Akaike Information Criterion. $\mathrm{LL}=$ Log-Likelihood. Continuous variables centered at their grand means. Reference category in parenthesis. $\dagger p<.10 ; * p<.05 ; * * p<.01 ; * * * p<.001$. 
Figure 1. Predictive Margin of Living Space Per Capita by Family Wealth and Communitylevel Poverty Rate Percentile
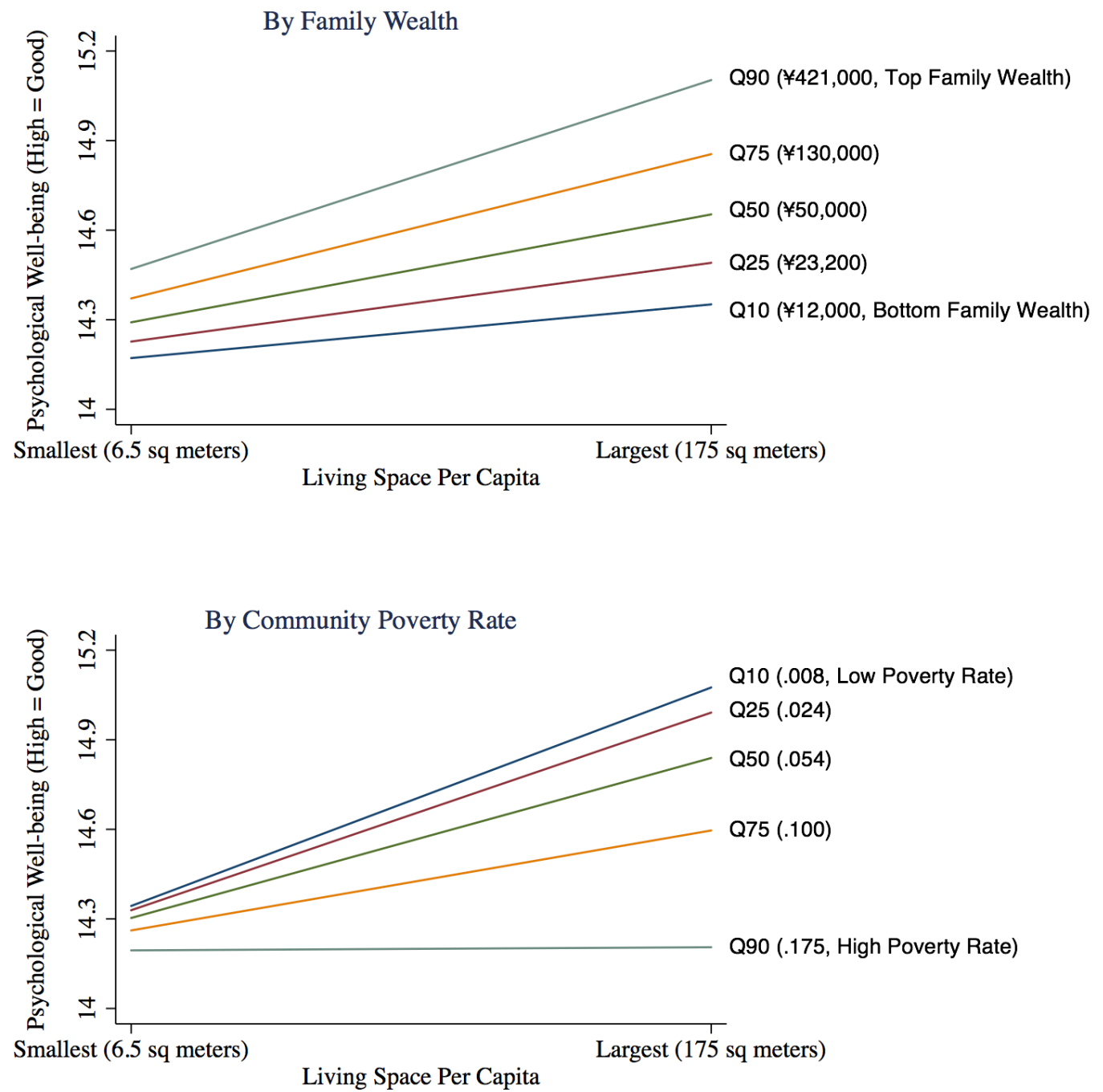

Note: Predictive margins calculated based on Model B and C in Table 3, with all covariates set at their mean levels of the sample and random effects set to 0 . Family wealth and community poverty rate at each percentile in parenthesis. 